\title{
Energy access and security strategies in Small Island Developing States
}

Franziska Wolf (corresponding author)

Hamburg University of Applied Sciences

Research and Transfer Centre Applications of Life Sciences

Ulmenliet 20, 21033 Hamburg/Germany

franziska.wolf@haw-hamburg.de

Dr Dinesh Surroop

Faculty of Engineering

University of Mauritius

Reduit

Mauritius

d.surroop@uom.ac.mu

Prof. Dr. Anirudh Singh

University of the South Pacific (USP)

School of Engineering and Physics

Private Mail Bag

Laucala Bay, Suva, Fiji

anirudh.singh@usp.ac.fj

Prof. Dr. (mult.) Dr. h.c. (mult.) Walter Leal

Hamburg University of Applied Sciences

Research and Transfer Centre Applications of Life Sciences

Ulmenliet 20, 21033 Hamburg/Germany 
walter.leal@haw-hamburg.de

\section{$\underline{\text { Abstract: }}$}

Small Islands Developing States (SIDS) are isolated and surrounded by ocean. The generation and use of energy resources are two very important aspects for the development of SIDS. Unfortunately, most of SIDS do not use their potential in respect of energy resources, and they as a result have to depend on the import of fossil fuels in order to meet their energy needs. This increases the overall vulnerability of SIDS as they have to depend on the rising or fluctuating fossil fuels prices. Some SIDS, especially in the geographically dispersed Pacific region, do not have proper access to energy whereas other SIDS struggle more with energy security issue. At the same time, SIDS are most vulnerable to the impacts and effects of climate change, as they are among the ones to be most severely affected in case of natural calamities and sea-level rise.

Drawing on experiences from Fiji and Mauritius, this paper explains core elements related to energy access and security in SIDS, contextualizes and discusses barriers and list some of the strategies that may be used to ensure access to and a continuous supply of energy in SIDS. A situational analysis of two SIDS outlines their current energy situation and compares their energy policies to globally accepted criteria for SIDS policies as well as with each other. It is claimed that the diverging energy performances of Fiji and Mauritius cannot be explained by policies differences. The reasons for the varying energy performances may therefore lie in the administrative and institutional mechanisms used by the two countries in implementing their energy policies. Finally, to enable SIDS to reduce their overall vulnerability and become truly sustainable islands, it is recommended to undertake careful assessments of the particular local contexts under which island energy regimes operate.

Keywords: Energy, Access, Security, policy, Fiji, Mauritius 


\section{Introduction}

Succeeding and expanding the Millennium Development goals (MDG), a set of 17 Sustainable Development Goals (SDG) provides UN member states since September 2015 with a new set of goals, targets and indicators which will frame policy agendas and influence policies over the next decade (UNDESA 2015). SDG 7 (SDG 7: Ensure access to affordable, reliable, sustainable and modern energy for all) relates to the issues of energy access and security, two issues which are highly relevant especially for Small island Developing States (SIDS). SIDS, however, face some island-specific challenges that limit their ability to secure the well-being and to provide sustainable livelihoods to current and future generations (Weisser 2004, Stuart 2006, Kelman and West 2009, UNDP 2011, Feinstein 2014; UNEP 2014; UN-OHRLLS 2015):

- Inherent characteristics of SIDS, e.g. smallness and remoteness, limited resources and a disproportional dependence on international trade, limit SIDS' ability to achieve economies of scale, create relevant internal markets or access capital to finance development action, i.e. influencing economic structure and performance;

- SIDS also rely heavily on fossil fuels to meet local energy demands, the cost of energy is among the highest of the world due to high fuels transportation costs, and, in general, they pay a higher price per unit of electricity than non-island countries.

In future, SIDS nations may have to face a set of island-specific emerging socio-economic challenges, among them the need for appropriately skilled capacities as well as a transition to renewable energy systems to support sustainable island livelihoods. Moreover, as societal development both relies on and leads to increased electricity consumption and transportation and manufacturing fuel needs (for an extensive review see, for example, Bayar and Özel 2014), a lack of access to and an insecure supply of energy can therefore substantially impede sustainable development in SIDS. 
Feinstein (2014) points towards a high energy vulnerability of SIDS, indicating that 13 out of 24 Pacific SIDS are classified as being most vulnerable to oil price shock, the cost of fuel imports in SIDS has a share of $12-37 \%$ of total imports, and many SIDS have to cope with interrupted supply. The recent GEO SIDS Outlook [4] provides a summary of key energy issues for these island nations, underscoring the importance and inherent island potential of renewable energy sources for SIDS (see table 1).

Concerning fossil fuel dependence in the Caribbean and the Pacific region, Niles (2013) states that energy consumption for commercial purposes is largely dominated by imported fossil fuels (see also Figure 1). The seemingly high access to electricity is thus greatly based on fossil fuels, with SIDS spending more than USD 67 million per day on oil (Feinstein 2014). As energy intensity is high and increasing, SIDS need to take measure to improve energy efficiency, and some having poverty rates above $20 \%$, must provide affordable energy services to allow access for everyone (Feinstein 2014).

Finally, modern energy services require increased energy production. Appropriate policies to accelerate the spreading and implementation of low emission technologies especially if they utilize renewable sources, to facilitate access and a secure, reliable supply of energy and promote energy efficiency, become more and more important (UN 2010). Taking into account local endowments and the distinctive constraints of island energy production, e.g. difficulties to achieve economies of scale, capacity issues, continued use of fossil fuels etc., are critical elements when designing energy policies for SIDS (Stuart 2006). This paper analyses the energy policy environments in Mauritius and Fiji, and show how these two SIDS approach the quest towards becoming sustainable energy islands.

\subsection{Energy Access}

The lack of access to modern energy services, sometimes also referred to as energy poverty, resembles a significant global development challenge (Dornan 2014). If the three major SIDS regions - i.e. African, 
Caribbean and Pacific SIDS - are compared, large differences in energy access can be noticed. Being extremely wide geographically dispersed, especially many islands in the Pacific SIDS region still lack adequate access to energy. Apart from some exceptions like Tokelau which is heavily solar powered and Fiji and Papua New Guinea which can utilize heavily hydro power resources, the Pacific region SIDS show rather low levels of electrification (see Figure 1).

\section{[insert new figure 1 here]}

Access to energy can contribute to a set of SDGs such as improved healthcare provision, better education, gender equality and poverty reduction (UN 2010). However, defining energy access is difficult as there is no common definition in the literature. Common features found in all definitions relate to the provision of energy services that are key to socio-economic development and may be classified underneath three broad headings:

- $\quad$ access to a minimum level of electricity, e.g. for lighting and communication;

- $\quad$ safer and more sustainable cooking and heating fuels and technologies; and

- access to modern energy services for productive uses, e.g. industry, and public services such as schools or street lighting

Related to the provision of these energy services are certain quality aspects such as technical availability, adequacy, reliability, convenience, safety and affordability (IEA 2015). In line with the understanding of affordability by the UN (2010), affordable energy would be compatible with local income levels, i.e. with a price level not higher than traditional fuels. Most SIDS are, however, unable to connect to a larger, possibly intercontinental grid like, for example, a global power grid proposed by Chatzivasileiadis et al. (20114), which may result in those affordable energy prices due to seizing economies of scale and cost spreading on a much larger customer base than just the population of one small island, so SIDS need to find other solutions, taking into account their internal constraints as well (Stuart 2006). Pointing towards sustaining economic growth, Weisser (2004:129) underscores that "the availability of adequate energy resources at a reasonable cost remains a vital precondition for continued economic growth." Weisser 
(2004) adds that the infusion of renewable technology may result in a lower cost of production, valid for both on- and off-grid applications.

SIDS are also distinctively marked by their high cost of energy in general as prices of petroleum products are much higher in SIDS than in other regions of the world, for example, in Pacific SIDS sometimes as much as 200-300\% (UNEP et al. 2012:17). As a result, households in the Pacific might have to spend up to $20 \%$ of their disposable income on energy. World market prices of crude oil fluctuate largely, and imported energy resources would need to be paid in foreign currencies whose exchange rates vary as well, placing additional burden on SIDS national accounts (UNEP et al. 2012; UNEP 2014; UNEP 2014a).

\subsection{Energy security}

Definitions of energy security span from a narrow view, focusing on disruptions of physical energy supply, to wider perspectives considering economic, environmental and political impacts and changes that influence energy markets (Dreyer and Stang 2013). Guiding policy design, the simplest, mainstream definition is by the International Energy Agency (IEA): "the uninterrupted availability of energy sources at an affordable price" (IEA 2015). Another, well-known framework in the study of energy security are the four As (availability, affordability, accessibility, acceptability). However, due to a lack of scientific credibility, recent research argues that " $a$ valid concept of energy security should be based on a concept of security in general'(Cherp and Jewell 2014: 416) that can be tailored to specific situations, for example, a SIDS context. A clear concept will enable policy-makers to better distinguish between alternative policies (Baldwin 1997) that should provide answers to key questions of security (see Baldwin 1997:13-17): Security for whom? Security for which values? From what threats? How much security at what costs and in what time?

Energy security has long-term and short-term dimensions (IEA 2015). According to its long-term dimension, energy supply needs to be balanced with economic growth. But world market prices of crude 
oil fluctuate largely, so imported energy resources place additional burden on SIDS national accounts (UNEP 2014; UNEP 2014a). Figure 2 illustrates that many of the African SIDS have made good progress towards increasing their energy security by reducing their reliance on fossil fuels, being able to meet a good share of their energy needs by renewable energies.

\section{[insert new figure 2 here]}

Short-term energy security relates to the ability of the respective energy system to cope with sudden changes, for example, the infusion of renewable energy into energy grids. SIDS will always have to deal with an inherent trade-off between seizing economies of scale in energy production and energy security. Weisser (2004) points out that many islands fail to achieve economies of scale as energy systems in SIDS often have an output smaller than $9 \mathrm{MW}$ which is said to be the threshold for full economies of scale of typical diesel-powered generators so commonly used in SIDS. However, the more capacity, the greater the capacity margin needed to ensure a reliable, uninterrupted supply of energy. For this reason, capacity management is a critical aspect for utilities and regulators, too (Stuart 2006). Distributed power systems, especially if they are based on renewable energy, can be designed in a modular way resulting in a more sustainable overall system (Stuart 2006).

In times of emergencies, electric power systems in islands face reliability problems since they cannot access continental grids. Due to their high vulnerability to natural hazards, it is a critical aspect that energy security policies need to be addressed. For example, recently, the tropical cyclone Winston, a category 5 extreme weather event, hit several islands, including the main island of the Fijian archipelago, leaving a trail of devastation. Major disruptions and power outages affected livelihoods as well as business and academic life heavily, i.e. energy security could not be guaranteed anymore. As a consequence, the main university, for example, had to shut down its operations for a week as a continuous supply of electricity at a level necessary to run its various university campuses could not be guaranteed, even with a reduction of power usage. Even under normal conditions, it is problematic that a 
reliable, secure provision of energy can only be guaranteed by utilizing fossil-fuel power plants to generate energy and electricity (Mayer 2000).

After a brief elaboration of the methodological approach of this paper, the authors undertook a comparative analysis of the two island states, namely Fiji and Mauritius, concentrating on key aspects related to energy access and energy security policies. In the subsequent discussion chapter, a critical look is taken at the energy strategies adopted by the two SIDS.

\section{Methodology}

To meet their distinctive energy needs and taking into account local conditions and abilities to satisfy those needs in a sustainable manner, SIDS in the Pacific region as well as other ACP SIDS which may not be as stretched out as the Pacific Island countries (PICs), require tailored policies (Singh et al. 2013). To explore in detail, how distinctive island states tackle the challenges of designing appropriate energy policies to improve their levels of energy access and energy security, case studies are an appropriate method to gain in-depth insights (Creswell 2009). The elements and core questions of the conceptual considerations will provide the frame of analysis.

Based on the findings of two case studies including Fiji, located in the Pacific Ocean, and Mauritius, located in the Indian Ocean, a comparison will be made to identify similarities and differences in the respective energy policies and their strategic orientations concerning energy access and energy security. Representing a Pacific SIDS, Fiji has been chosen as illustrative example for the particularly energy access dimension characteristic for the region whereas the analytic focus on Mauritius puts the energy security dimension in the focus of attention. As the University of Mauritius and the University of the South Pacific, Fiji, are both partnering in the EDULINK project L3EAP - Lifelong Learning for Energy Access, Security and Efficiency in African and Pacific Small Island Developing States (www.project-

13eap-eu), Fiji and Mauritius were selected as target countries for this comparative study. The comparison consists of the current status of the energy mix and analyses energy access, security and efficiency 
dimensions. It also looks into prevailing energy strategies and energy-related targets as well as barriers to energy access and security. Based on the comparison and critical analysis of the case study, the results lead to possible solutions and certain measures are proposed for improvement. Finally, a detailed analysis is carried out to identify tshe reasons for the difference in energy performance of the two SIDS.

\section{Comparative analysis of Fiji and Mauritius}

The following section provides a comparison of two selected countries from the Pacific region (Fiji) and the African region (Mauritius). In a logical manner, the island's power sector, its grid, its electricity demand, its electricity supply and the kinds of sustainable technologies implemented are described, followed by a brief overview of current policies affecting the development of the energy sector.

\subsection{Overview of the energy sector in Fiji}

Fiji's land area of $18,333 \mathrm{~km}^{2}$ is distributed amongst approximately 300 small islands spread out over a sea surface area of 1.3 million $\mathrm{km}^{2}$. The two largest islands of Viti Lev and Vanua Levu together account for $87 \%$ of the total land area. Some $85 \%$ of the total population of 850,000 are accommodated on these two main islands.

The varied geology of Fiji, which is not dis-similar to that of its Pacific neighbours, subjects the country to the same energy issues. Examples of these are the lack of indigenous fuel resources, geographical remoteness and inadequate infrastructure, human capacity and institutional mechanisms to develop and produce energy technologies locally (Singh and Gosai 2015).

The scattered topography of Fiji not only makes transportation and general accessibility difficult, but also means high differential costs of basic commodities and high risks of supply chain disruptions for the outer island (or maritime region) rural communities. The same diversity of topography also pre-determines the nature of the energy strategy adopted by the country. Because large "national" grid electrification 
schemes can only be economically viable for the larger islands, Fiji and many of the PICs have resorted to a two-prong energy strategy: a national grid scheme for the largest islands and rural electrification schemes for the others. The power distribution systems of Fiji thus consist of large "national" grids, managed by the Fiji Electricity Authority (FEA) on the one hand, and mini village grids (maintained by village communities), the Ministry of Works grids (maintained by the Ministry of Works) and Solar

Home Systems for individual households for the outer islands. The largest of the national-scale grid, supplying Viti Levu, uses the 80 MW Monasavu and 40 MW Nadarivatu hydro schemes, supplemented by diesel power generation. In 2013 about $61 \%$ of the electricity was generated from hydro and $38 \%$ from diesel generators (FEA, 2012). The rest was provided by Independent Power Producers (IPPs) that contributed between 2 to $3 \%$ of Fiji's electricity, with wind and solar providing around 1\% of FEA power. These statistics are summarized in Table 1 below. The FEA provides grid connected power to 89\% of the Fiji population (Fiji Energy Forum 2015; Singh and Gosai 2015).

\section{[insert table 1 here]}

Electricity demand has increased at 5\% per annum recently and the total peak load is about 138 MW. FEA's installed capacity is currently close to $215 \mathrm{MW}$. The electricity mix (see Figure 3 ) shows that hydro has generally exceeded diesel and HFO generation except for the year 2010 when they were equal. With the extra 40 MW hydro capacity added in 2012 through the Nadarivatu project, the renewable generation now has an assured lead over fossil fuel sources (Singh and Gosai 2015).

\section{[insert Figure 3 here]}

Fiji has taken up the challenge of electrifying its rural areas with the use of small diesel genset-based village grids and individual Solar Home Systems (SHS). A typical solar home system will consist of a ( $100 \mathrm{~W}$ ) solar panel, charge-controller/battery and inverter system that can power a few low-wattage light bulbs and a power-point. The rural power generation scenario as it stood in 2014 is summarized in Table 2. 
[insert Table 2 here]

A minimum level of electrification can be achieved for rural communities through either individual home electrification via SHS or the provision of mini-grids. The Fiji Department of Energy (FDOE) began installing the Solar Home Systems (SHS) as early as 1983, starting with a few dozen systems at Namara village in Kadavu and Vatulele village in Koro (IRENA 2013).

For the higher power consumption needs of the average rural household, devices such as diesel generator sets (gensets) and nano-hydro (pico-hydro) systems are more appropriate. The former solution however entails the issue of diesel supply to the remote outer islands, the supply-chain economics of which can become quite daunting. The use of alternative diesel engine fuels produced from locally-available sources is a possible solution. These can be either pure plant oil (PPO) such as coconut oil (CNO), or the chemically derived fuel known as biodiesel (Demirbas A., 2011; Santori G., 2012; Singh P., 2010).

Fiji and the rest of the PICs can produce coconuts in abundance. In the case of Fiji, enough biodiesel can be produced to provide all the B5 (a fuel blend consisting of 5\% biodiesel and 95\% petroleum diesel) needs for the country (Singh 2012). However, producing biodiesel is not cost-effective when compared to the price of petroleum diesel in Fiji's outer islands. A cheaper alternative is to use coconut oil in engines with modified fuel injection systems, or to use CNO-diesel blends.

Small hydro schemes provide another means of power generation for the rural setting. Hydro-power schemes are usually classified as large/medium (> 15 MW), small (1-15 MW), mini (100kW-1MW), micro $(5-100 \mathrm{~kW})$ or nano/pico $(<1 \mathrm{~kW})$. Mini/micro hydro schemes are frequently the most appropriate for village electrification. Those that existed in Fiji in 2014 are listed in table 3 below. The $700 \mathrm{~kW}$ Lomolomoa mini-hydro scheme is currently under construction in Taveuni.

[insert Table 3 here]

\subsection{Energy policies in the Pacific region}


PICs have been aware for some time of the importance of policy in the sustainable development of their energy sector. While the PICs have many energy issues in common, there are also many differences in their energy needs and their ability to satisfy them (Singh el al 2013). Thus there is a need for energy policy development at both the regional and national levels.

\subsubsection{Regional policy issues}

The first regional energy policy to be attempted was the Pacific Island Energy Policy and Plan (PIEPP 2002). It was developed in 2002 and was revised in 2003 to strengthen the renewable energy (RE) component. Problems with the PIEPP became evident as early as 2004 (Wade et. al 2005). It became evident that the policy had to be revised, and the Pacific Leaders at the Pacific Islands Forum Meeting in Cairns, Australia in August 2009 agreed to review the PIEP and its associated Action Plan (PIESAP). The document that resulted from this decision was the Framework for Energy Security in the Pacific (FAESP) (FAESP 2010) and its associated implementation plan, which were endorsed by the Pacific leaders in 2011.

\subsubsection{The Fiji National Energy Policy (FNEP)}

Fiji's first National Energy Policy was adopted in 2006. This was reviewed in 2013 to account for the many developments in the country since the policy was first inacted, chief amongst these being the UN Secretary-General's SE4ALL by 2030 initiative. This revised document, the Fiji National Energy Policy 2013 (FNEP 2013), which has yet to be passed by cabinet, has the main objectives of providing access for all Fiji citizens to modern energy services and increasing the efficient use of energy and the use of indigenous energy sources to reduce the costs of energy imports on Fiji (Singh and Gosai 2015).

The document sets targets according to the three objectives of the UN SE4ALL by 2030 initiative. They are universal access to modern energy services, doubling the global rate of improvement in energy efficiency and the share of renewable energy in the global energy mix by 2030. It provides specific 
policies for grid-based power supply, rural electrification, renewable energy, the transport sector, petroleum and biofuels, and energy efficiency.

The Fiji government has realized that to achieve success at both the small-scale (rural community) and larger scale (urban electrification) levels, it needs support from the private sector. There is a need for private sector investment, especially in the form of Small to Medium Enterprises (SMEs). This has led the country to embark on the Fiji Renewable Energy Power Project (FREPP). The aim of the Fiji Renewable Energy Power Project (FREPP) is the removal of all barriers to private sector investment in the generation of grid-connected RE-based power in Fiji (FREPP, 2015). The program has already produced resource assessments of the waste-to-energy potential for grid-power generation in Fiji.

In summary, Fiji which has a similar geography to many of the other PICs, shares many of the same energy challenges. Two of these are the dependence on (expensive) imported fossil fuels, and the difficulty of energy supply/distribution to the outer (smaller) islands. The country has met these challenges by firstly adopting a two-pronged energy strategy where the electrical energy needs of the largest islands are served by national grids operated by the Fiji Electricity Authority, and rural electrification schemes for the small outer islands comprising of mini-grids or the recently-introduced solar home systems. The country is able to rely on the abundant hydro resources to meet much of its larger generation needs. It has a robust energy policy with well-defined renewable energy and energy efficiency targets to meet its energy challenges.

\subsection{Overview of the energy sector in Mauritius}

Located in the Indian Ocean, the Republic of Mauritius is a tropical Small Island Developing State (SIDS). It consist of two island namely Mauritius which is the main island and Rodrigues. The Indian Ocean comprises of several islands namely Seychelles, Comoros, Madagascar, Rodrigues and Reunion which is a French Overseas department. Madagascar is the largest island in the Indian Ocean and Mauritius is located $800 \mathrm{~km}$ from the eastern part of Madagascar. The Mauritian economy is mainly 
based on tourisms, textile, sugar and global offshore. The island has a total population of around 1.26 millions inhabitants (CSO, 2014). Although facing many constraints, the Mauritius economy has performed quite well where the gross national income (GNI) at market price is around 10000 million USD (CSO, 2015).

Mauritius is one of those few islands that provide electrification to the whole population (REN21, 2015). Being an island surrounded by sea, there is not enough resources in terms of oil, gas and coal to supply power. Therefore, the fossil fuels resources are imported and as such the island is vulnerable to the changes in oil prices. Though all the population in the island have access to power, energy security remains a problems mainly with the changes in oil prices and with ongoing debates on climate change.

Electricity is generated by the national utility company called Central Electricity Board (CEB) and Independent Power Producers (IPP), however, the CEB is responsible for power distribution and transmission. The island has established infrastructure with grid connection in all part of the island where there is inhabitants which ensure power access. Power is produced by a mix of fossil fuels and renewable energy although it is dominated by fossil fuels namely oil and coal. Power is produced through steam turbine where high pressure and temperature vapour is fed in the turbine when using coal and biomass as fuel. In the case of oil, engines are used for power generation and there is also gas turbine power plant that operates only at peak demand. The renewable energy technologies are mainly hydro, wind, landfill has, solar and bagasse. Around 3.000 GWh of power was generated in 2014 to meet the energy demands in the island. Table 4 shows the power generated from different sources in 2014.

\section{[insert Table 4 here]}

Figure 4 shows the share of power generated from different sources. $79.7 \%$ of power is produced from fossil fuels which are mainly coal and oil and $20.3 \%$ is produced from renewable energy out of which bagasse is the dominant one representing $15.5 \%$. 
The World Bank conducted a study in 2015 on the assessment of electricity demand forecast and generation expansion plan for the period 2015-2017 (World Bank, 2015). The report provides short and long term recommendations which are as follows:

- It is recommended that the operation of the existing power plants that are scheduled for decommissioning and the contract of IPPs that is scheduled for termination are extended for a short term solution.

- It is recommended to have new capacities to meet the future demand for a long term solution

- It is also recommended that for both short term and long term the utility company must review and improve the methodologies used for the planning of expansion of the technologies.

\subsection{Energy policy in the Indian Ocean region}

The Indian Ocean Islands have their own specificity. Pacific and Caribbean region have many SIDS which are more or less close to each other, and many of the islands consist of several small islands. Different to Caribbean and Pacific SIDS, there are only a few SIDS in the Indian Ocean region. Energy security is the most common issue among all the SIDS while energy access differs from island to island: Seychelles and Mauritius have the highest electrification rate with $97 \%$ and $100 \%$ respectively.

\subsubsection{Regional policy}

Given that all the SIDS in the region face the same challenges, there is a urgent need to come up with a regional policy on energy which can be supplemented by national policies. The five islands in the Indian Ocean, namely Comoros, Madagascar, Seychelles, Mauritius and Reunion (located in the Indian Ocean, it belongs to the Republic of France, though) cooperate well among each other. There are some projects linking the islands that are often coordinated by Indian Ocean Commission (IOC), an intergovernmental organisation. Although there are many projects with respect to energy and renewable energy in the regions, there is hardly any common regional policy. In fact each island has their own policy in terms of energy. 


\subsubsection{The Mauritius Energy policy}

Given that the demand of energy has kept on increasing and the prices of fossil fuels have been fluctuating, there has been many strategies that have been proposed in order to ensure energy security for the islands. The following are few of the strategies proposed:

\section{Long Term Energy Strategy:}

The Ministry of Renewable Energy and Public Utilities (2009) developed a long term energy strategy for the period 2009 - 2025. The objective of the Long Term Energy Strategy is to propose measures and strategies in order to reduce the dependence of fossil fuels and to increase the share of renewable energy in the energy mix by developing renewable energy technologies. Table 5 shows the strategy to increase the share of renewable energy up to 2025 .

\section{[insert Table 5 here]}

\section{Integrated Electricity Plan $2013-2022$ :}

The Central electricity Board (CEB) which is the utility company responsible for transmission and distribution of power has come up with an Integrated Electricity Plan in 2013 for the period 2013 - 2022. The plan is a continuation of what has been proposed in the Long Term Energy Strategy 2009 - 2025. The Integrated Electricity Plan 2013 -2022 provided a list of new renewable energy projects as shown in Table 6 below.

\section{[insert Table 6 here]}

\section{Results and Discussion}


Before taking a more critical look at the energy strategies adopted by the two SIDS, it is instructive to consider how their policies meet the criteria for successful energy policies as enunciated generally in the literature.

\subsection{Strategies for energy access and energy security in SIDS}

Generally, strategies to foster energy access and security in SIDS must take into consideration the prevailing developmental strategies. Many SIDS strive to provide cheap energy to their population as it is widely recognized that access to electricity has positive welfare effects (Dornan 2014). “As a result, fossil-fuel-based electricity provision is often subsidized in the belief that this brings faster economic growth and fosters social development" (Weisser 2004:134-135). Existing SIDS policies therefore often continue to promote the electricity provision from fossil fuels even though it resembles an enormous challenge to SIDS which are among the most indebted countries in the world, caused partly by rising energy prices, and which allocate $60-70 \%$ of their gross domestic product for oil imports and debt financing (Feinstein 2014; UNEP 2014). Moreover, this practice, overall, does not only lead to increasing CO2 emissions from SIDS but it is counter-productive. Subsidies keep the price of electricity production for fossil fuels low compared to renewable energy, thus, discourage energy saving and lower the demand for energy efficient appliances (Weisser 2004).

In the two case studies presented in the previous chapter, the policy makers have shown a clear understanding of these negative aspects of fossil fuel use through strategies that actively seek to reduce this reliance via the use of indigenous energy resources.

In terms of improving the access to electric energy, two generic strategies can be pursued. Firstly, grid extension, mostly confined to rural and peri-urban areas, and secondly, off-grid provision of energy, often witnessed in rural areas. The literature points towards a certain competition of those energy strategies which can impact SIDS' energy budget planning as there is "to some extent a trade-off between the two; extension of the grid leaves less funding available for off-grid electrification" (Dornan 2014:18). 
Access to off-grid energy can be facilitated through readily available, cost-efficient conventional diesel generators as well as renewable technologies if households are able to bear the upfront costs, or through government or donor-funded electrification programs. Niles (2013) found a significant impact of donor programmes on Caribbean and Pacific SIDS by supporting investment in energy technologies, both conventional and renewable, but criticized that a substantial transition to more sustainable energy sources has not yet taken place in those SIDS.

In the present situation, off-grid electricity is provided mainly through stand-alone diesel gensets and solar home systems (in the case of Fiji). The possible competition between grid-extension and off-grid electricity noted above is a non-issue in the case of Fiji's outer islands, due to their small-scale electricity requirements which makes grid electricity unviable.

Moreover, it has been suggested that the operation and maintenance of especially renewable energy systems remains a challenge due to lack of knowledge and skills, poor quality products and a lack of regulations (Dornan 2014) which is why donors increasingly support capacity-building in energy related topics for relevant stakeholder groups to build and strengthen local capacities (see, for example, the EDULINK project L3EAP, www.project-13eap.eu).

Grid extension offers a more reliable supply of energy, however, it may not be financially feasible for rural areas as implementing the relevant infrastructure requires high upfront costs. Here, output-based approaches, i.e. awarding Energy Service Companies (ESCOs) or Renewable Energy Companies (RESCOs) with certain subsidies if they provide rural electrification, can foster private investment for grid extension; this approach has been trialed in Pacific SIDS, with mixed success (Dornan 2014). Grid extension is feasible in the case of Mauritius, but can only provide partial solution to the national electrification programme of Fiji due to the noted geographical limitations.

It can thus be said that, on the whole, the current energy policies of the two SIDS have been designed appropriately to meet their energy challenges. Through such means, Mauritius has managed to use its 
meagre indigenous energy resources to meet its current demands, and has well-formulated plans for the utilization of more of its energy resources in the future. Similarly Fiji also has policies that are welldesigned to tackle its energy challenges. In the latter case however, geographical consideration pose an additional element of challenge. Fiji has adapted to the situation via a two-pronged energy framework.

At first sight therefore, both countries have energy frameworks that ostensibly cater for their energy demands adequately. However, greater insights can be gained into the performance of the two nations through a direct comparison of their policies.

\subsection{Comparing the energy frameworks of Fiji and Mauritius}

Some key characteristics related to the distinctive energy policies of Mauritius and Fiji are summarized below in Table 8 . It provides a comparison of the current share of energy production (conventional vs renewable energy) of Fiji and Mauritius, their distinctive energy characteristics, strategies and targets, energy access and security aspects, and lists the current energy targets.

\section{[insert Table 7 here]}

The comparison firstly reveals that Fiji is relatively abundant in renewable energy resources, in particular hydro energy which is a stable source of energy supply. Mauritius on the hand is relatively energy resource-poor in terms of hydro energy. Both countries have energy policies in place that provide adequate bases for the development and maintenance of energy sectors to cater for their national energy needs.

Mauritius boasts $100 \%$ energy access. That figure is significantly below this level for Fiji is due at least in part to its geographical layout. It is impracticable to set up grid systems on most of the 300 islands of the archipelago, where the only plausible solution is provided by off-grid power sources including standalone diesel generators and Solar Home Systems. Mauritius consist of two main islands (Mauritius and 
Rodrigues) and it is relatively much easier to have a grid where the whole populations are connected compared to Fiji which is more diverse in terms of the many archipelago.

The question of energy security may be viewed in two parts. The first is the stability and reliability of the country's own energy sources. Secondly, the reliance of the nation on imported fuels always means that it becomes susceptible to a multitude of supply-related issues, including supply chain issues and oil price shocks in particular. The above comparison reveals that Fiji, with a large hydro resource, is assured of a more stable grid electricity supply. However, it suffers from (imported) diesel fuel supply chain issues to its outer islands. Both Fiji and Mauritius are prone to oil price shocks.

Fiji is targeting to increase the renewable energy share to $81 \%$ by 2020 while Mauritius is targeting to reach $35 \%$ by 2025 . Yet the plain comparison of the existence of energy policies and targets does not sufficiently explain the different performance of the two island states. Comparing the amount of energy generated in the two countries, Fiji $(857,500 \mathrm{MWh})$ shows only about $30 \%$ of what Mauritius is able to produce $(2,932,600 \mathrm{MWh})$. It is obvious that Mauritius has a much larger supply of energy to meet its developmental needs and sustain economic growth than Fiji-As an added indicator of this imbalance, note that the amount of energy per capita in Fiji is $1 \mathrm{MWh}$ as compared to $2.3 \mathrm{MWh}$ in Mauritius. The reason for this difference in energy performance must therefore lie elsewhere.

\subsection{Towards improved energy access, security and efficiency}

The explanation of the difference in performance needs a critical analysis of all possible energy strategies and how they feature in the two case studies. Some of the most important elements and key aspects of successful energy strategies can be related to (i) policy and regulatory frameworks; (ii) infrastructure; (iii) incentives; (iv) energy efficiency; (v) financing:

i) Policy and regulatory framework:

The foremost strategy for SIDS is to come up with a policy or framework to set the road map of the country which will demonstrate the political intention. The policy will set the plan in terms of energy 
access, security or share of renewable energy for future both on short and long term basis. The policy will lead to sustainable energy solutions by implementing the set target. The targets should not be too ambitious and it should be set with consultation with all the relevant stakeholders to ensure its implementation. Both Fiji and Mauritius have policy frameworks that address their energy development needs in a comprehensive and realistic manner.

\section{ii) Infrastructure}

In order to increase access to energy, there must be an appropriate medium through which energy can be accessed. In most of the cases, energy can be access through the grid and absence of grid can deprived this access mainly in the rural region. The grid connection can either be extended so that it can reach all the people or in case of remote and isolated region off-grid electrification system can be envisaged. The use of grid systems to deliver power to the urban and peri-urban regions is an integral part of the transmission systems for both Mauritius and Fiji. In the case of the latter, limitations as noted above prevent the establishment of grids on the small outer islands. The country's rural electrification scheme provides alternative solutions in such cases. SIDS like Fiji where there are many archipelagos and that are less dense, off-grid electrification would be an appropriate solutions. However, SIDS where the mainland are densely populated and yet no access to electricity, extension of the existing grid system can be considered.

iii) Incentives

Given that poverty is one of the barrier to energy access, proper incentive, as far as possible, must be provided to the people. The incentive can be in terms of subsidy on LPG for cooking so that people can have access to clean energy for cooking and this can decrease the number of people affected by indoor air pollution from burning of biomass. SIDS are blessed by unlimited sun resources round the year. The incentive can be a grant on solar water heater so that people can avoid electricity or LPG for heating water. This scheme proved to be a big success in Mauritius. The grid was recently opened in Mauritius 
whereby individual household could produce their own power through photovoltaic and the excess power could be fed on the grid. The utility company purchased the excess power at a higher rate so as to give incentive to people for producing power from renewable sources. The absence of an effective netmetering scheme such as above in Fiji can be attributed to the lack of the appropriate legislation that regulates such sales and purchases of electricity. This however is a minor issue and is unlikely to contribute significantly to the difference in energy performance between the two countries.

\section{iv) Energy Efficiency Initiatives}

Energy efficiency measures lead to reduction in energy losses which guarantee the security. Energy security can therefore be enhanced by energy efficiency initiatives. Energy efficiency can be in the form of:

1. Replacement of inefficient bulbs by efficient one as it is the case in Mauritius with the CFL bulb

2. Reducing transmission and distribution losses

3. Using efficient cooking stoves

4. Implementing energy efficient standard and labelling

5. Implementation of building codes

The use of energy efficiency measures in reducing energy consumption is well established in Mauritius. In Fiji, programmes to implement similar measures have been in place at least since the beginning of this decade.

v) Financial Instruments

Financial aspects in energy access and security are of upmost importance. No policy can be implemented without adequate financial backing. There are many financial schemes that can be tapped in order to overcome the financial hurdles. Some of the schemes that can be accessed by SIDS are, for example: 
1. Global Environment Facility (GEF). Many islands have benefitted from GEF to ensure energy security. A small scale hydropower project was implemented in Madagascar. In Mauritius, programmes were funded to removed barriers to renewable energy, improve energy conservation in building. Grid connected PV system was funded in Seychelles (REN21, 2015).

2. Clean Development Mechanism (CDM). Projects on renewable energy technologies that can demonstrate greenhouse gases mitigation can be funded under the CDM or voluntary carbon mechanism.

3. Carbon finance support. Nationally Appropriate Mitigation Actions (NAMA) which consist mainly of energy efficiency or renewable energy projects can be funded.

4. Green Climate Fund. This is another scheme that can help SIDS to implement any mitigation measures.

All these financial opportunities have been utilized by Mauritius (as noted) as well as Fiji in to varying extents.

On various governance levels, a number of initiatives are in place for SIDS to promote sustainable energy and policy frameworks, provide certain infrastructure and incentivize stakeholders in the frame of dedicated programmes and projects, and build capacities for improved interlinkage with global financing schemes. Promising examples are, for example, UNEP's "Sustainable Energy4All (SE4ALL)" and the International Renewable Energy Agency's (IRENA) recent "SIDS Lighthouse Initiative" on a global level. The "Framework for Action on Energy Security in the Pacific (FAESP)" or the "SIDS DOCK", an initiative of the Alliance of Small Island States (AOSIS) are rather regional energy policy frameworks (IRENA 2014; SIDS DOCK 2011). IRENA's global roadmap aims to double the share of renewables in the world's energy mix between 2010 and 2030, currently assisting a set of islands to develop national road maps for RE deployment and grid integration in the frame of its newly established Global Renewable Energy Island Network (GREIN) (Gielen 2013; IRENA 2015). Examples of relevant national level strategies from the ACP region are Fiji's National Energy Policy, the Republic of Mauritius' Long- 
Term Energy Strategy 2009 - 2025 or the 2009 Sustainable Energy Framework for Barbados. It must be noted, though, that some of these initiatives were developed by regional governing institutions themselves addressing inherent aims whereas others were initiated by global organizations pursuing other objectives.

In summary, after considering all the important criteria for the success of energy strategies, it is found that Fiji appears to be at par with Mauritius in most instances. The difference must therefore be due to other factors. One such possibility that has not been well-charted in the literature is the role that administrative and institutional mechanisms play in the formulation, implementation and maintenance of policy initiatives. Examples of such mechanisms include the establishment and adherence to timelines, and proper administrative and accounting procedures to ensure delivery of expected outcomes. They also include institutional memory to ensure that, for instance, projects implemented in the past are always part of the present schedule of activities. The above analysis has revealed that even when different SIDS adhere to the basic requirements of sound energy policy-making, it is possible that their performances may still differ greatly. The causes of such divergences in performance make an interesting subject for future research.

\section{Conclusions}

This paper considers the energy strategies of two SIDS (Mauritius and Fiji) against the general criteria for successful energy policies as stipulated in the literature, and then compares the key features of the two policy frameworks to obtain greater insight into their relevance. It finds that both SIDS seem to possess a clear understanding of the basic principles of sound energy policy-making. Comparison of the two policy frameworks shows Fiji to be more energy resource-rich. However both countries have energy policies in place that are appropriate for their energy requirements. While Fiji has a slight advantage over Mauritius in its large hydro potential which is an excellent source of stable electricity supply, both countries are prone to fossil fuel supply-related challenges such as oil price shocks. 
A critical analysis is carried out of all possible energy strategies of relevance to SIDS in an attempt to identify the cause of the difference in energy performance between the two countries. It is concluded that both Fiji and Mauritius are for the most part equally compliant with the key policy criteria for SIDS. It is finally concluded that the cause of the difference in energy performance may lie in the possible difference in the administrative and institutional mechanisms employed by the two countries.

\section{Acknowledgements}

The authors are grateful to the anonymous reviewers for their constructive feedback and recommendations which substantially improved the quality of this paper. It has been produced in the frame of the EUDULINK project "L3EAP - Lifelong Learning for Energy Efficiency, Security and Access in African and Pacific Small Island Developing States" (www.project-13eap.eu) and comprises some of the insights presented in the frame of the "International Conference on Energy, Energy Efficiency and Climate Change (ICEECC2015)”, held in Mauritius from 8-9 July 2015.

\section{References}

APERC, Asia Pacific Research Centre (2007), a Quest for Energy Security in the $21^{\text {st }}$ century: Resources and Constraints, Institute of Energy Economics, Japan.

Bayar, Y., Özel, H.A. (2014), Electricity Consumption and Economic Growth in Emerging Economies, Journal of Knowledge Management, Economics and Information Technology, 4 (2), April 2014

Baldwin, D.A. (1997), The concept of Security, Review of International Studies, 23:5-26.

Creswell, J.W. (2009), Research Design, Qualitative, Quantitative and Mixed Method Aproaches, SAGE, US/UK/Singapore. 
Chatzivasileiadis, S., Ernst, D., Anderssson, G. (2014), Global Power Grids for Harnessing World Renewable Energy, in: Jones, L.E. (ed), Renewable Energy Integration: Practical Management of Variability, Uncertainty and Flexibility in Power Grids, Academic Press, Boston, 175-188.

Cherp, A., Jewell, J. (2014), The concept of energy security: Beyond the four As, EnergyPolicy75:415-421. CEB (2013). Integrated Electricity Plan 2013 - 2022. Central Electricity Board.

CSO (2014). Mauritius in Figures. Central Statistics Mauritius. Government of Mauritius

Demirbas A., (2011). Competitive liquid biofuel from biomass. Applied Energy 88:17-28.

Dornan, M., (2014), Access to Electricity in Small Island Developing States of the Pacific: Issues and Challenges, Renewable and Sustainable Energy Reviews, 31:726-735.

Draft Strategic Action Plan (2013), www.fdoe.gov.fj, accessed on 10 November 2015.

Dreyer, I., Stang, G. (2013), What energy security for the EU, Brief issue 39, http://www.iss.europa.eu/uploads/media/Brief_39_Energy_security.pdf, accessed on 11 August 2015.

FAESP (2010). Towards an energy secure Pacific - a Framework for Action on Energy Security in the Pacific, Secretariat of the Pacific Community (SPC). Available at www.spc.int

FEA (2012) Annual Report 2012, Fiji Electricity Authority, Suva, Fiji

FEA (2013) Annual Report 2013, Fiji Electricity Authority, Suva, Fiji

Feinstein, C. (2014), SIDS - Towards A Sustainable Energy Future, presentation held in the frame of the Worldbank - UN High Level Dialogue on Advancing Sustainable Development in Small Island Developing States, 13 June 2014, Washington D.C., http://www.worldbank.org/content/dam/Worldbank/SIDS\%20Towards $\% 20$ Sustainable $\% 20$ Energy $\% 20$ Future.pdf, accessed on 12 August 2015.

FDOE (2015). Fiji Department of Energy website www.fdoe.gov.fj

Fiji Energy Forum, (2015). Fiji Clean Energy Investors’ Forum. 9 April 2015. Holiday Inn, Suva, Fiji. www.youtube.com/watch?v=E-tctBd9D1

Fiji Department of Energy (2014). Sustainable energy for all (SE4ALL): Rapid assessment and gap analysis. FREPP, (2015) Fiji Renewable Energy Power Project, www.fdoe.gov.fj. 
IEA (2014), World Energy Outlook 2014, Factsheet, http://www.worldenergyoutlook.org/media/weowebsite/2014/141112_WEO_FactSheets.pdf, accessed on 11 August 2015.

IEA (2014), World Energy Outlook Special Report. Africa Energy Outlook. A Focus on Eneryg Prospects in Subsaharan Africa,

https://www.iea.org/publications/freepublications/publication/WEO2014_AfricaEnergyOutlook.pdf, accessed on 10 March 2016.

IEA (2015), Topic Energy Security, http://www.iea.org/topics/energysecurity/, accessed on 11 August 2015.

IPESP (2011) Towards and energy secure Pacific - Implementation Plan for Energy Security in the Pacific (IPESP 2011-2015), Secretariat of the Pacific Community (SPC). Available at www.spc.int

IRENA (2013) Pacific Lighthouses. Renewable Energy Opportunities and Challenges in the Pacific.Islands Region. IRENA (2014), IRENA Lighthouse Initiative, http://www.irena.org/menu/index.aspx?mnu=Subcat\&PriMenuID=44\&CatID=112\&SubcatID=458, accessed on 15 March 2015.

IRENA (2015), REmap 2030 - A Renewable Energy Roadmap, https://www.irena.org/remap/, accessed on 12 August 2015.

Mayer, P.C. (2000), Reliability economies of scale for tropical island electric power, Energy Economics 22:319330.

MREPU (2009). Long Term Energy Strategy 2009-2025. Ministry of Renewable Energy and Public Utilities.

PEC, (2012). Fiji Solar Home Systems Project. Available at www.forumsec.org/resources/.../PEC-Fund-Fiji.pdf PIEPP (2002) Pacific Islands Energy Policy and Plan, October 2002, available at www.forumsec.org REN21 (2015). SADC Renewable Energy and Energy Efficiency: Status Report. Renewable Energy Policy Network for the $21^{\text {st }}$ Century.

Santori G Di Nicola, G., Moglie, M., Polonara, F. (2012). A review analysing the industrial biodiesel production practice starting from vegetable oil refining. Applied Energy. 92:109-132.

SIDS DOCK 2011, SIDS DOCK Support Program for Small Island Developing States, retrieved 3 March 2015, from http://www.esmap.org/node/3033m. 
Singh P.J., Khurma, J., Singh, A. (2010). Preparation, characterization, engine performance and emission characteristics of coconut oil based hybrid fuels. Renewable Energy. 39 (9):2065-2070.

Singh, A. (2012). Singh, A. Biofuels and Fiji's Roadmap to Energy Self-Sufficiency. Biofuels. 3(3):269-284.

Singh, A., Fifita, S., Mario, R., Bijay, P. (2013), Sustainable Energy Development in the Pacific: The Evolution of Energy Frameworks and National Policies, in: Leal Filho, W., Mannke, F., Mohee, R., Schulte, V., Surroop, D. (2013), Climate smart Technologies, Integrating Renewable Energy and Energy Efficiency in Mitigation and Adaptation Responses, Springer, Berlin/Heidelberg, 129-140.

Singh A (2015). Towards sustainable energy for all in the Pacific: Charting Fiji's road to success. Asia-Pacific Tech Monitor, April-June 2015, Available at http://www.techmonitor.net/tm/index.php?title=Asia-Pacific_Tech_Monitor Singh, A. Gosai, A. (2015), Climate change policy and sustainable energy development in Fiji: implication to Pacific island states, in: Leal, W. (2015), Climate Change in the Asia Pacific Region, 10.1007/978-3-319-14938-7, Springer International Publishing, Switzerland, 263-280.

UN (2010), The Secretary-General's Advisory group on Energy and Climate Change (AGECC), Energy for a Sustainable Future, Report and Recommendations, New York.

UNDESA 2015, Sustainable Development Knowledge Platform, Open Working Group proposal for Sustainable Development Goals, https://sustainabledevelopment.un.org/sdgsproposal, accessed on 6 August 2015)

UNEP (2014), Global Environment Outlook, Small Island Developing States, United Nations Environment Programme (UNEP), Division of Early Warning and Assessment, Nairobi, Kenya.

UNEP et al. 2012, UNEP, UN DESA and FAO, 2012, SIDS-FOCUSED Green Economy: An Analysis of Challenges and Opportunities, www.unep.org/greeneconomy and www.unep.org/regionalseas, ISBN: 978-82-7701-105-9.

UNEP (2014a), UNEP 2014. Emerging issues for Small Island Developing States. Results of the UNEP Foresight Process, United Nations Environment Programme (UNEP), Nairobi, Kenya.

Wade H, Johnston P and Vos J. (2005). Pacific Regional Energy Assessment 2004, Regional Overview Report, Vol 1, SPREP, Apia, Samoa.

Worldbank (2015), Countries and economies, data.woldbank.org/country; accessed on 11 August 2015.

World Bank. (2015). Assessment of electricity demand forecast and generation expansion plan with focus on the 2015-2017 period. 